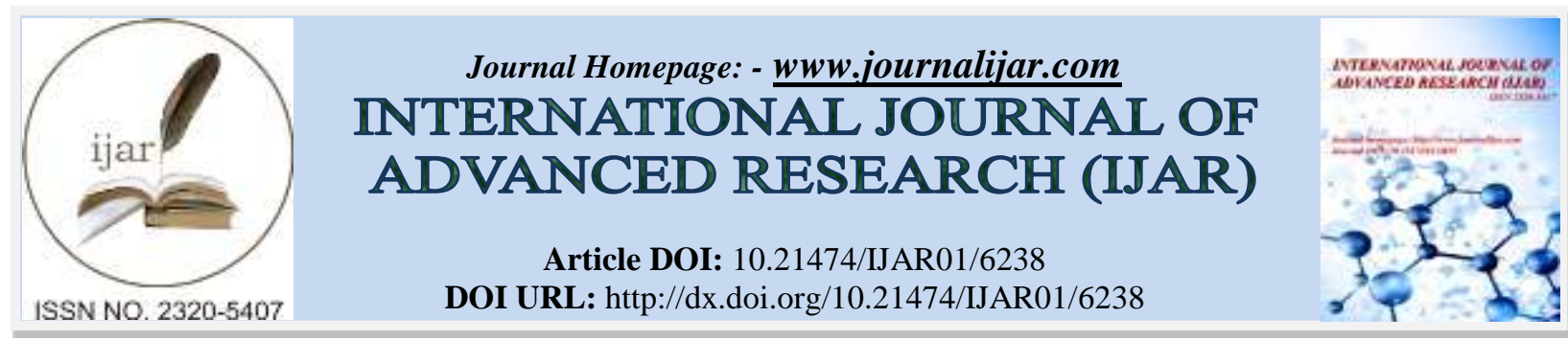

RESEARCH ARTICLE

\title{
AN UNUSUAL NECK SWELLING: MALIGNANT GANGLIONEUROMA, A RARE ENTITY.
}

\section{Dr. Chaitya Shah ${ }^{1}$, Dr. Arun Kumar Haridas ${ }^{2}$ and Dr. Kirtana Shah ${ }^{3}$.}

1. Resident, Department of General Surgery, S.B.K.S. Medical Institute and Research Center, Pipariya, Vadodara.

2. Head and Professor, Department of Cardiothoracic and vascular Surgery, S.B.K.S. Medical Institute and Research Center, Pipariya, Vadodra.

3. Resident, Department of General Surgery, S.B.K.S. Medical Institute and Research Center, Pipariya, Vadodara.

\section{Manuscript Info}

\section{Manuscript History}

Received: 06 November 2017

Final Accepted: 08 December 2017

Published: January 2018

Keywords:-

Ganglioneuroma, Horner's Syndrome, Neuroblastoma, Ganglioneuroblastoma.

\section{Abstract}

Introduction: Ganglioneuroma $(\mathrm{GN})$ is a rare, benign, non-invasive and neurogenic tumour. It has a neuroectodermic origin and is localized along the sympathetic trunk. Due to its rarity and the lack of specific signs and symptoms it is often difficult to reach definite diagnosis prior to surgical exploration and complete surgical excision and pathological examination. Material and Method: A 6 year old female presenting with swelling in the right side of neck associated with difficulty in breathing to the out-patient department of Cardiothoracic Surgery of Dhiraj Hospital was selected. Result and Analysis: The patient was discharged on post-operative day 9 with stable vitals and no postoperative complications. Discussion: It has a higher female predominance and commonly presents as an enlarging neck mass. In the neck due to proximity to the thyroid gland it occasionally presents with signs of Horner's syndrome. Though usually asymptomatic, they may sometimes cause symptoms when vital structures are compressed or when there are high levels of catecholamine. MRI and CT are the mainstay of diagnosis for such tumors. Malignant ganglioneuromas are rare. Surgical excision of ganglioneuromas is the mainstay of the treatment.

Copy Right, IJAR, 2018,. All rights reserved.

\section{Introduction:-}

Ganglioneuroma of the neck is a rare tumor usually seen in children and young adults less than 20 years of age. They arise from sympathetic system and it's benign in nature. It has a higher female predominance and commonly presents as an enlarging neck mass. In the neck due to proximity to the thyroid gland it occasionally presents with signs of Horner's syndrome. It also causes compression of vital structures in the neck. Clinically and radiologically these lesions can be mistaken as something else. Common sites are adrenal gland, retroperitoneum, mediastinum and rarely neck $(8 \%)$. We report a case of mediastinal ganglioneuroma extending into the neck in a 6 years old female child.

\section{Case Report:-}

A 6 years old female child presented with a right side neck swelling since 1 year. The swelling was gradually increasing in size, painless and associated with difficulty in breathing. There was no associated dysphagia or fever. On local examination it was approximately about $6 \mathrm{~cm} \times 4 \mathrm{~cm}$ swelling in right supraclavicular region and was non-

Corresponding Author:- Chaitya Shah.

Address:- Resident, Department of General Surgery, S.B.K.S. Medical Institute and Research Center, 
tender, mobile but not moving with protrusion of tongue. FNAC result showed hypocellularity with occasional pleomorphic cells with prominent nucleoli with enlarged nucleus and abundant cytoplasm suggestive of malignant tumor. USG suggested ill-defined, heterogenous, predominantly hyperechoic solid mass lesion with internal macrocalcification and subtle areas of necrosis and minimal internal vascularity of size $6.1 \times 4.1 \times 2.8 \mathrm{~cm}$ in right supraclavicular region and extending in right infra-clavicular region displacing trachea to left side. The lesion also displaced and compressed the adjacent carotid vessels. CT scan of Neck and Thorax suggests a large mild enhancing soft tissue mass lesion measuring $7.5 \times 7 \times 7 \mathrm{~cm}$ in right side superior mediastinum with supra clavicular extension abuting and displacing trachea to left side. It also abuts right common carotid artery, subclavian artery and vertebral artery without significant luminal narrowing. It compresses internal jugular vein with complete luminal occlusion. There is no evidence of necrosis, calcification or cystic area. During surgery (In Total Excision) there was a large 20 x $10 \mathrm{~cm}$ dumbbell shaped mass in right supraclavicular region extending in the neck, behind clavicle in right thoracic region abutting the right lung, right CCA, right IJV, right subclavian artery and vertebral artery completely engulfed by tumor. Posterior portion of tumor engulfed multiple nerve roots with multiple scalene group of lymph nodes and large retro aortic lymph node. Histology was suggestive of Ganglioneuroma (Schwannian StromaDominant) category, Maturing subtype, Stage IIB. Ipsilateral regional lymph nodes: single scalene lymph node shows presence of tumor. Other lymph nodes and thymus shows no evidence of tumor. Procedure was un-eventful with an uneventful post-operative course. Patiient was discharged on post-operative day 9 and is doing well on follow-up.
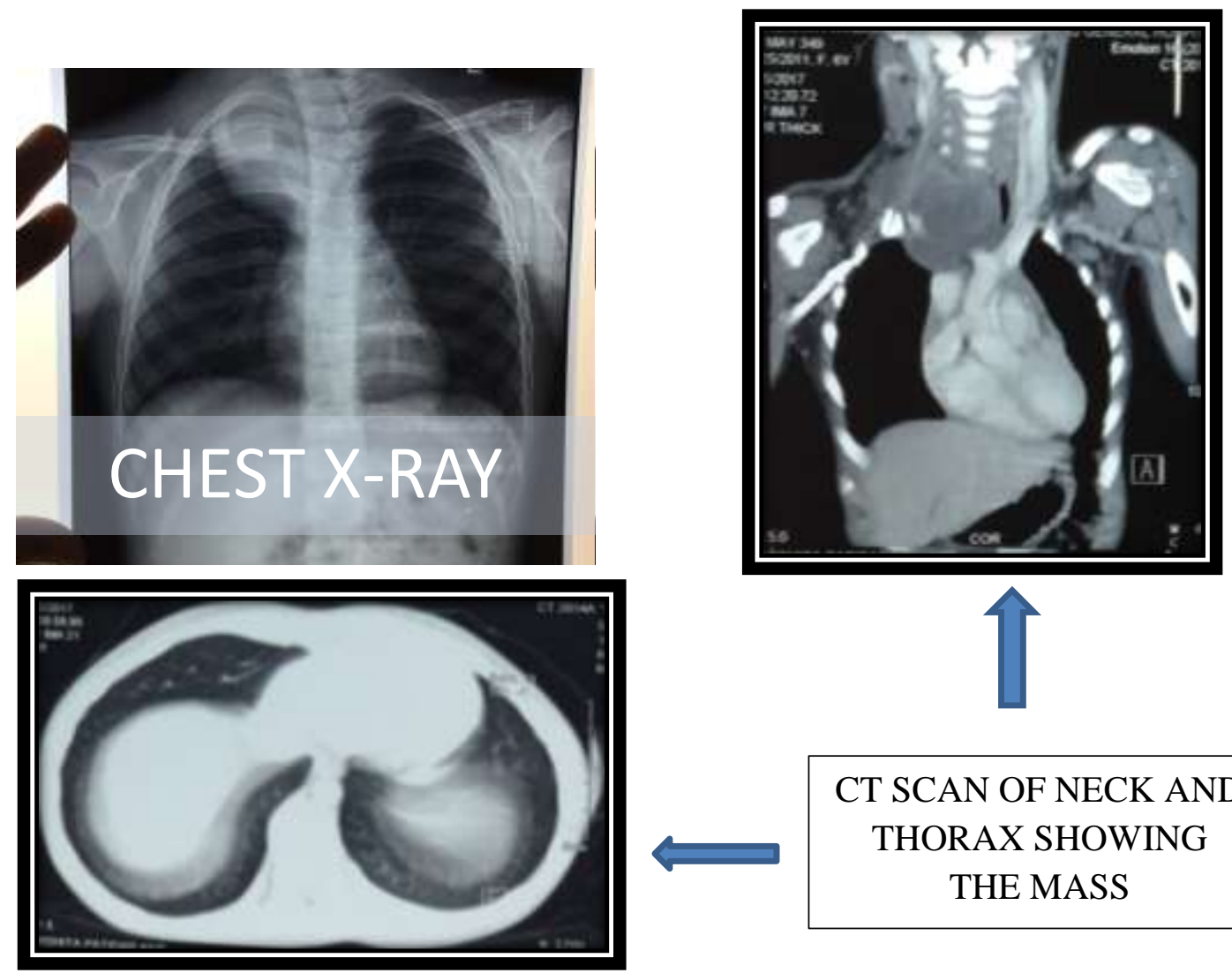

CT SCAN OF NECK AND THORAX SHOWING THE MASS 

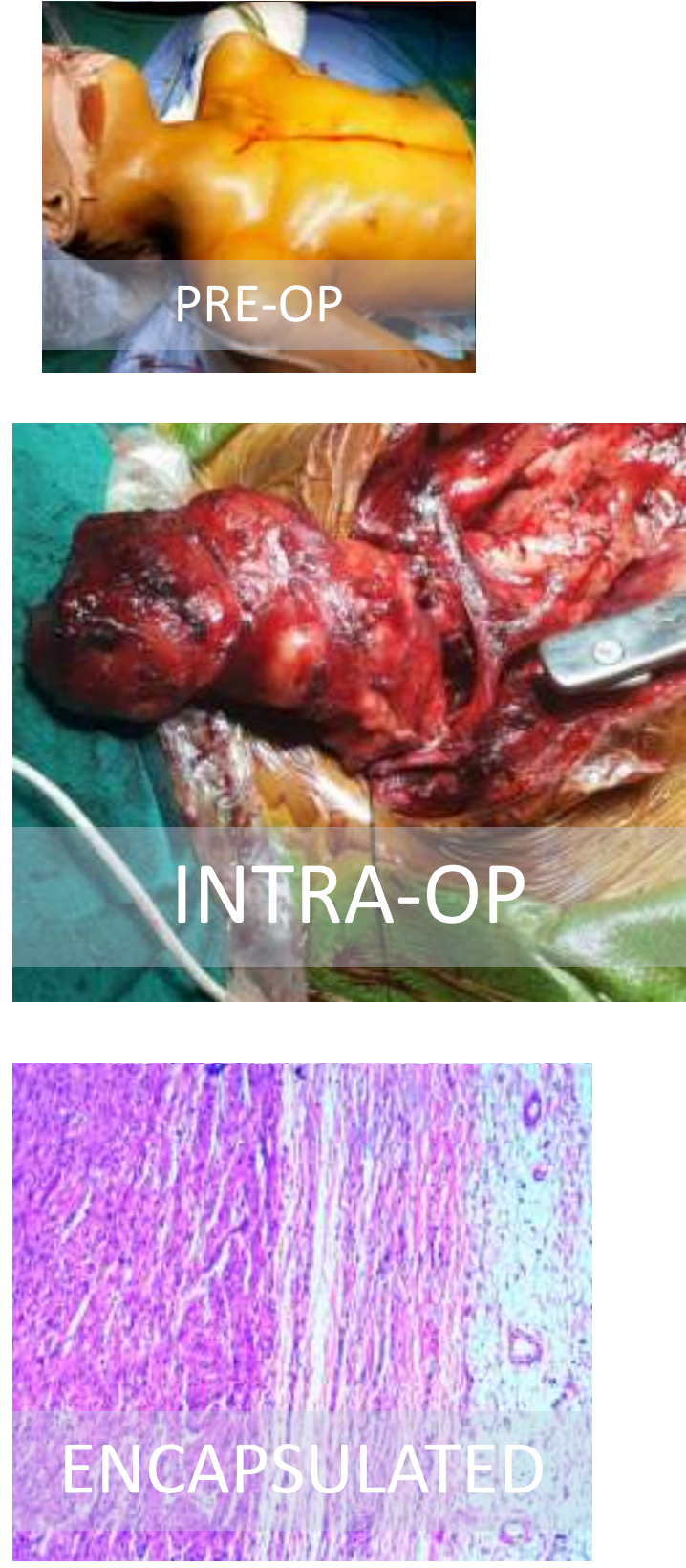
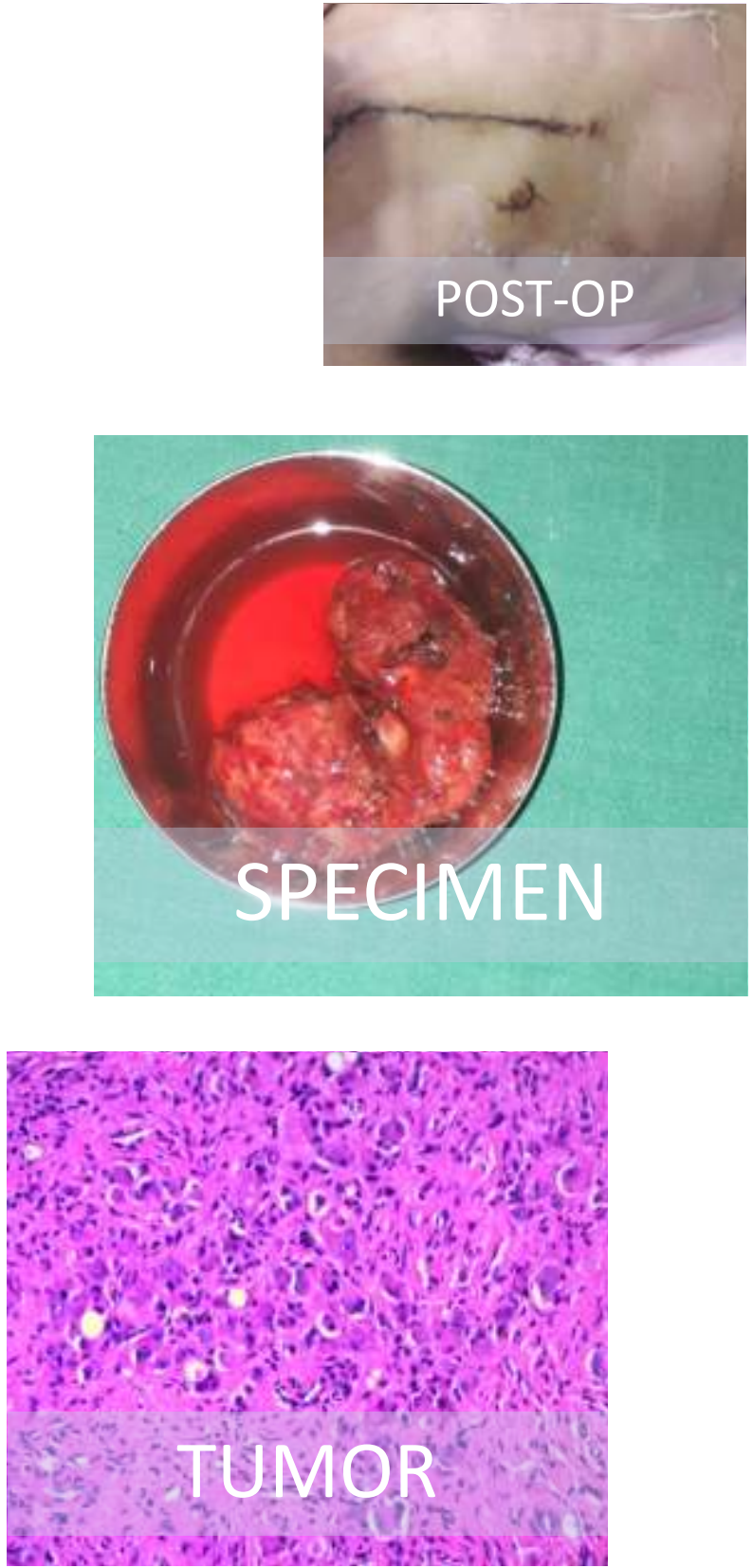

\section{Discussion:-}

Loretz first reported ganglioneuroma in 1870 while De Quervain in 1899 first reported ganglioneuroma of neck [1]. Cervical ganglioneuroma, benign tumors of neurogenic origin, are rare and account for $6 \%$ of childhood tumors [2]. They arise from cervical sympathetic chain [3]. Elsewhere in the neck region they arise from the larynx, pharynx, and the hypoglossal nerve, along the length of the vagus and the intervertebral foramina and thereby extending to even the spinal cord. Ganglion cells, Schwann and stroma are the component of such tumors [4]. Though usually asymptomatic, they may sometimes cause symptoms when vital structures are compressed or when there are high levels of catecholamines. Increase in catecholamine level lead to rise in levels of VMA and HMA in plasma or urine resulting in hypertension, diarrhoea, flushing, sweating, renal acidosis and other symptoms of catecholamine excess [5]. In a case report by Junli, there was only one case of multiple ganglioneuroma on one side of neck while 3 cases with bilateral neck masses over a period of 10 years. MRI and CT are the mainstay of diagnosis for such tumors. Such tumors have capsule and calcifications. Radiologically it is impossible to differentiate between ganglioneuroma, neuroblastoma and ganglioneuroblastoma. On FNAC the characteristic finding of ganglioneuroma 
is presence of mature ganglion cells but in $25 \%$ of the cases immature neurogenic tumors can be seen. Macroscopically they appear encapsulated but true capsule is infrequent. Histological appearance of more than $50 \%$ presence of Schwann cell population along with neuroblastic cells confirms the diagnosis. The metaiodobenzylguanidine scan (MIBG) is trusted to show $88 \%$ sensitivity and $99 \%$ specificity for these tumours along with carcinoid and pheochromacytoma. Immunohistochemistry, in which ganglion cells stain for neuron specific enolase (NSE) and Schwann cells stain for S-100 protein [6]. Usually malignant ganglioneuromas are rare. They represent metastases of neuroblastoma or ganglioneuroblastoma which have later matured to ganglioneuroma. Such patients have excellent prognosis. Our case is that of malignant ganglioneuroma.

Peripheral neuroblastic tumors represent a spectrum of diseases from undifferentiated and malignant NB to welldifferentiated and benign GN [7].

International neuroblastoma pathology classification (the Shimada System)

1. NB (schwannian stroma-poor)

2. Intermixed GNB (schwannian stroma-rich)

3. Nodular GNB (schwannian stroma-rich/stroma-dominant and stroma-poor)

4. GN (schwannian stroma-dominant),

5. Maturing

6. Mature.

Surgical excision of ganglioneuromas is the mainstay of the treatment. These tumors being non aggressive donot recur and residual compnents of the tumors also shall not cause any symptoms. Complication from surgery for cervical ganglioneuroma is the injury to compressed vascular and neural structures mostly resulting into Horner's syndrome, but its symptoms resolve soon. Chemotherapy and bone marrow transplantation are also used in the treatment [8]. Radiotherapy should be avoided in children as it increases the risk of growth retardation and tumor development secondary to radiation [9].

\section{References:-}

1. Kaufman MR, Rhee JS, Fliegelman LJ, Costantino PD. Ganglioneuroma of the parapharyngeal space in a pediatric patient. Otolaryngol Head Neck Surg. 2001; 124: 702-704.

2. Califano L, Zupi A, Mangone GM, Long F. Cervical Ganglioneuroma: report of a case. Otolaryngol. Head Neck Surg. 2001; 124: 115-116.

3. Katilmis H, Ozturkcan S, Adadan I, Ozdemir I, Algın H, Tunakan M. Cervical ganglioneuroma. Int J Ped Otorhinolaryngology. 2006; 1: 157-159.

4. Georger B, Hero B, Harms D, Grebe J, Scheidhauer K, Berthold F. Metabolic activity and clinical features of primary ganglioneuromas. Cancer. 2001; 91: 1905-1913.

5. Geoerger B, Hero B, Harms D, Grebe J, Scheidhauer K, Berthold F. Metabolic activity and clinical features of primary ganglioneuromas. Cancer. 2001;91:1905-1913.

6. J.Q.Trojanowski ,W.M.Molenar., D.L.Baker D.L: Neural and neuroendocrine phenotype neuroblastoma, ganglio-neuroblastoma, ganglioneuroma and mature versus embryogenic human adrenal medullary cells. Prog.Clin. Biol. Res.; 366: 1991 ,335-341,.

7. Cannady SB, Chung BJ, Hirose K, Garabedian N, Van Den Abbeele T, Koltai PJ. Surgical management of cervical ganglioneuromas in children. Int J Pediatr Otorhinolaryngol. 2006;70:287-294.

8. K.E. Bove, A. J. Mc Adams : Composite ganglioneuroblastoma an assessment of the significance of histologic maturation in neuroblastoma diagnosed beyond infancy. Arch Path Lab Med ,105,1981, 325.

9. H.Shimada , I.M.Ambros ,L.P. Dehner : Terminology and morphologic criteria of neuroblastic tumours. Recommendations by the International Neuroblastoma Pathology Committee. Cancer 86,1996 349-363. 